\title{
Measuring the economic values of natural resources along a freeway: a contingent valuation method
}

\begin{abstract}
Natural resources are often victims of development. On the one hand, a freeway is under construction, while on the other hand there are unique natural resources along the route of the freeway. Both of them are essential to us. Thus, we cannot ignore either of them. The purpose of this study is to find the monetary equivalent of the natural resources in response to a challenge between environment and development. Dealing with non-use values, we apply the contingent valuation method (CVM). Our results show that the mean of willingness to pay (WTP) is US\$1.84 per household for supporting natural resources along the route of the freeway. Total WTP for supporting natural resources along the route of the freeway is US\$77 million annually. The findings indicate that Iranian people have a high sensitivity for supporting natural resources along the route of the freeway. Hence, the government should give more attention to natural resources along the freeway and change its route.
\end{abstract}

Keyword: Natural resources; Contingent valuation method; Willingness to pay; Non-use values; Logit model 